\title{
Aedes aegypti CONTROL PROGRAMMES IN BRAZIL
}

\author{
H. R. C. ARAÚJO ${ }^{1,3}$, D. O. CARVALHO ${ }^{2}$ AND M. L. CAPURRO ${ }^{1,3}$ \\ ${ }^{I}$ Department of Parasitology, Institute of Biomedical Sciences, University of São \\ Paulo, São Paulo,SP, Brazil; mlcapurro@gmail.com \\ ${ }^{2}$ Joint FAO/IAEA Division, Insect Pest Control Laboratory, Seibersdorf, Austria; \\ d.carvalho@iaea.org \\ ${ }^{3}$ National Institute of Science and Technology in Molecular Entomology, Medical \\ Biochemistry Institute, Federal University of Rio de Janeiro, Brazil
}

\begin{abstract}
SUMMARY
Mosquito-borne diseases are among the most significant challenges facing societies around the world. In Brazil, current official epidemiological reports show increasing numbers of cases of mosquito-borne diseases, such as chikungunya, dengue, yellow fever and Zika, which are spreading to new areas of the country. Therefore, it can be stated that current methods used for the management of mosquito vectors in Brazil, established since 2002, have been ineffective. Thus, there is a necessity for readjustment or updating of the Aedes aegypti control programmes that are being applied in Brazil. As recommended by the World Health Organization (WHO), the best way to combat these pathogen vectors is an integrated approach where several convenient and compatible control techniques are combined to efficiently reduce or potentially eliminate a targeted insect vector population. In this manuscript, we updated a review published in 2015 by the same authors about Aedes control programmes in Brazil showing their basic concept and the principal components of Aedes integrated control programmes. Strategies such as public education, community engagement and responsibility; mechanical elimination of mosquito breeding habitats; the use of larvicides and adulticides; massive collection of eggs and adults using traps; and the reduction in the vector population through the promotion of sterility of mosquitoes by ionizing radiation, use of symbiont bacteria such as Wolbachia, or genetic modification, are discussed. The Brazilian experience to test and evaluate some of these technologies is described and compared with strategies to prevent and manage mosquito populations in other countries. It is concluded that there are new control methods that can be integrated on an area-wide basis to suppress mosquito populations successfully. Nevertheless, epidemiological studies are also needed to evaluate their impact on disease transmission, in addition to the proof-of-concept that they suppress mosquito populations.
\end{abstract}

Key Words: Mosquito control methods, community engagement, Projeto Aedes Transgênico, population suppression, integrated vector management (IVM), genetically modified mosquitoes, vector-borne diseases, Plano Nacional de Controle da Dengue (PNCD) Development and Field Application, pp. 339-366. CRC Press, Boca Raton, Florida, USA. (C) 2021 IAEA 


\section{INTRODUCTION}

\subsection{Aedes aegypti Primary Vector of Arboviruses}

Aedes aegypti (L.), the yellow fever mosquito, is the primary mosquito vector of various arboviruses such as yellow fever (YFV; genus Flavivirus), dengue (DENV; genus Flavivirus), Zika (ZIKV; genus Flavivirus) and chikungunya (CHIKV, genus Alphavirus).

Yellow fever is endemic in tropical areas of Africa, as well as Central and South America. Symptoms include fever, headache, jaundice (origin of the name "yellow" fever), muscle pain, nausea, vomiting, and fatigue. A small proportion of patients develop severe symptoms and approximately half of those die within 7 - 10 days (WHO 2018).

Dengue is endemic in more than 100 countries and is one of the most serious public health problems in the world. Clinical manifestations of dengue virus infection include high fever $\left(40^{\circ} \mathrm{C}\right)$ that can be accompanied by severe headache, pain behind the eyes, muscle and joint pains, nausea, vomiting, swollen glands or rash. It is estimated that worldwide, about 40\% (2500 million people) of the human population is at risk of contracting dengue fever, and about 390 million people are each year becoming infected with the disease. In 2016, more than 2.38 million cases of dengue were reported in the Americas, of which 1.5 million cases occurred in Brazil, i.e. a threefold increase in cases as compared with 2014 (WHO 2009, 2016a).

A ZIKV infection brings complications and consequences such as microcephaly in babies and the Guillain-Barré syndrome, and their neurological complications are being intensively investigated. Symptoms are generally mild and include fever, rash, conjunctivitis, muscle and joint pain, malaise or headache that last for 2-7 days. However, most people with Zika virus infection do not develop symptoms. Since the 1960s, ZIKV disease has been reported in Africa, Asia, the Pacific islands, and the Americas, but since 2015, its geographic range has expanded rapidly (WHO 2016b). Currently, the ZIKV has been reported in more than 84 countries, territories or subnational areas in the world (WHO 2017a). Between 2015 and 2017, more than 200000 confirmed autochthonous cases of ZIKV were reported in the countries and territories in the Americas, as well as 3323 confirmed cases of congenital syndrome associated with ZIKV infections. Of these ZIKV cases, a majority (134 057) were reported in Brazil (PAHO/WHO 2016).

CHIKV has been identified in over 60 countries in Asia, Africa, the Americas and Europe. The disease is characterized by fever and is frequently accompanied by joint pain, which is often very debilitating and lasts for a few days or weeks. In 2016, there were more than 150000 laboratory confirmed cases of chikungunya fever in the Americas. Brazil reported 146914 confirmed cases, followed by Argentina (322 confirmed cases) and Paraguay (38 confirmed cases) (PAHO/WHO 2014; WHO 2016c, 2017b).

All the above-mentioned viruses are transmitted by Aedes spp. when the female mosquitoes take a blood meal from a viremic human host and bites another nonviremic human host. These mosquitoes are distributed throughout tropical and subtropical territories, where they largely overlap, explaining their current scenario of co-infection (Furuya-Kanamori et al. 2016; Rückert et al. 2017). 


\subsection{Why Vector Control?}

The co-distribution and/or co-transmission of vector-borne diseases pose a challenge for public health in endemic and epidemic regions of the world, in particular also in Latin America (Furuya-Kanamori et al. 2016; Rodriguez-Morales et al. 2016; Carrillo-Hernández et al. 2018; O Silva et al. 2018; Suwanmanee et al. 2018). More than $80 \%$ of the global human population lives in areas where they are at risk of contracting at least one vector-borne disease and more than half lives in areas where they are at risk of contracting two or more of these diseases (PAHO 2016). Vectorborne diseases mainly affect poorer populations and impede economic development through direct and indirect medical and other costs such as loss of productivity and tourism (WHO 2017c).

Despite the emergence of new viruses transmitted by Ae. aegypti, dengue continues to be one of the most important public health problems in Brazil, considering the burden of disease and the great potential for evolution to death (Martelli et al. 2015; Araújo et al. 2017). Between 2013 and 2016, the cost of hospitalizations for dengue paid by Brazil's publicly funded health care system (known by the acronym SUS) was BRL 68.1 million (SHS 2017). In addition, dengue contributes to the loss of healthy years of life, affecting a large number of people from all age groups, causing some degree of disability during the infection period and deaths, mainly in children (Araújo et al. 2017). The application of remediation measures during epidemic periods can drastically reduce its cost through a more effective prevention programme using entomological surveillance, integrated with area-wide vector control strategies, resulting in the prevention of several diseases and increasing human population life quality in the target area.

In Singapore, for example, the haemorrhagic fever induced by dengue infection became a significant cause of death in the 1960s, affecting especially children. A vector control programme was implemented from 1968 to 1973, using data from entomological and epidemiological surveys to develop a strategy that was based on entomological surveillance, larval source reduction, public education, and law enforcement. The philosophy of the programme was to carry out vector control before the disease is detected as a means to reduce disease transmission. Singapore successfully controlled Ae. aegypti population and as a result, DENV infections were reduced and disease incidence remained low for a 15-year period. However, this success proved to be temporary, and the disease incidence increased again in the country in the 1990s (Ooi et al. 2006). The development of a local entomological index correlates the increase of new areas with breeding sites more supceptible to dengue transmission (Ong et al. 2019). In addition, cases of other arboviruses were reported, such as CHIKV in 2008 (Leo et al. 2009) and ZIKV in 2016 (Maurer-Stroh et al. 2016).

The reduction in the density of the Ae. aegypti population, the resurgence of DENV and appearance of other diseases transmitted by this vector seems like a paradox. However, it is speculated that several factors may have contributed to an increase in dengue incidence in Singapore: 1) decreased herd immunity after 30 years of low dengue exposure, 2) an increase in the proportion of adult infections, 3) virus transmission occurring outside houses, 4 ) the adoption of a reactive rather than a pro- 
active approach to vector control, 5) the presence of asymptomatic persons, and 6) a continued introduction of the virus through increasing numbers of travelers returning from endemic areas (Ooi et al. 2006; Ooi and Gubler 2009). Moreover, peridomestic areas, where other competent vectors were present (Aedes malayensis (Colless) and Aedes albopictus (Skuse)), were not included in the vector management programme (Mendenhall et al. 2017), and hence the programme was not following area-wide principles.

In the 20th century, classic vector control strategies to reduce populations of mosquitoes that transmitted malaria, yellow fever and dengue temporarily reduced the impact of these diseases in several countries using mainly insecticides (NASEM 2016). However, the current distribution of vector-borne diseases in the world shows that these and other disorders are re-emerging and/or spreading to new areas. This means that the full potential for preventing disease transmission is not applied as it should. There are factors that contribute to the failures such as technical complexity, costs and logistic needs, complacency and environmental concerns about insecticides (Townson et al. 2005).

\subsection{Aedes aegypti Control in Brazil}

Control of Ae. aegypti in Brazil has been implemented according to the guidelines outlined in the National Plan for Dengue Control (in Portuguese, Plano Nacional de Controle da Dengue - PNCD) (MS/FNS 2002), which is aligned with the Integrated Management Strategy for Dengue Prevention and Control in the Region of the Americas (known by the abbreviation IMS-Dengue) approved in the Resolution CD44.R9 adopted by the 44th Directing Council of the Pan American Health Organization/World Health Organization (PAHO/WHO 2003; San Martín and Brathwaite-Dick 2007).

The main objective has been to promote a model for prevention and control of dengue that incorporates national and international experiences and emphasizes the need for change in previous models, including also the decentralisation of the vector control programme so that each municipality is responsible for the control with the support from the State Department of Health and the Ministry of Health (MS/FNS 2002; Tauil 2002; Brasil 2009; PAHO 2018). The main actions involve epidemiological surveillance, vector control, patient care, integration with primary health care, environmental sanitation actions, integrated health education actions, communication and social mobilization, training of human resources, social and political support and evaluation of the programme (MS/FNS 2002, 2009; Braga and Valle 2007; Araújo et al. 2015).

The strategies involve the participation of 'Community Health Agents' (CHA) that are responsible, together with the local community, to promote the mechanical (removal or elimination of potential breeding sites) and chemical control (insecticides) with the objective of guaranteeing the sustainability of the elimination of breeding sites by real estate owners, in an attempt to break the chain of transmission of dengue. Other actions also recommended by the Brazilian Ministry of Health include installations of screens on the doors and windows to prevent the entry of the adult mosquito, in addition to the use of predators or pathogens with 
potential to reduce the vector population (biological control). Among the available predators are fish and aquatic invertebrates, which eat the larvae and pupae, and pathogens that release toxins including bacteria, fungi and parasites (Zara et al. 2016).

Since the mid-1980s, temephos (organophosphate) has been the main insecticide used against larvae of Ae. aegypti in Brazil. However, since 2002, mosquito populations in half of the country have become resistant to temephos (Chediak et al. 2016). As a result, pyriproxyfen, an insect growth regulator that mimics a natural hormone and interrupts insect development, was introduced in 2014 for the suppression of Ae. aegypti larvae (MS 2014a). Since 2009, malathion (organophosphate insecticide) has been used to control adults, replacing the use of pyrethroids after the identification of high levels of knockdown resistance registered (Martins et al. 2009). Concentrations of the all insecticides currently used, as well as the applied bioassay protocols, are those recommended by the WHO (2013) and the Brazilian Ministry of Health (MS 2014b).

Despite the risk of favouring the rise and dispersal of resistant populations, and the consequent lack of alternative insecticides to the currently available malathion against Ae. aegypti adults, the Brazilian Ministry of Health intensified insecticide spraying against Ae. aegypti, as a response to the Zika and chikungunya epidemics. The reliance on a strategy that was mainly based on chemicals to bring the Ae. aegypti population under control gave the human population in Brazil a false conception of security (Augusto et al. 2016). The unprecedented spread of vector-borne diseases clearly highlights the challenges faced by everyone, not just the health agencies. Multiple control tactics will need to be used for the management of vector-borne diseases, and this will only be possible if an integrated vector management (IVM) approach is selected. An IVM approach was adopted in 2004 by WHO for all vectorborne diseases and involves a rational decision-making process for the optimal use of resources, to improve cost-effectiveness, ecological soundness, and sustainability of disease-vector control (WHO 2004, 2008, 2017c). The outcome of IVM is improved human capacity and strengthened infrastructure to increase the well-being, and not only protecting human population against disease. The WHO recommends integrated control of the mosquito vectors, mainly those of dengue. Control activities should target Ae. aegypti (or any of the other vectors depending on the evidence of transmission) in all its immature (egg, larva, and pupa) and adult stages (WHO 2017d). The critical components of Aedes integrated vector management programme in Brazil are illustrated in Fig. 1.

\section{EDUCATION, COMMUNITY ENGAGEMENT AND RESPONSIBILITY}

\subsection{General Overview}

Of primary importance in any IVM strategy is training of health personnel in community-based participation so that the local population can understand and hence participate in several aspects of vector control (Gubler and Clark 1996; Ulibarri et al. 2016). Vector control also requires national level support to provide strategic direction, technical expertise, and training, aside from the development of norms and indicators to monitor the progress of operational activities. 


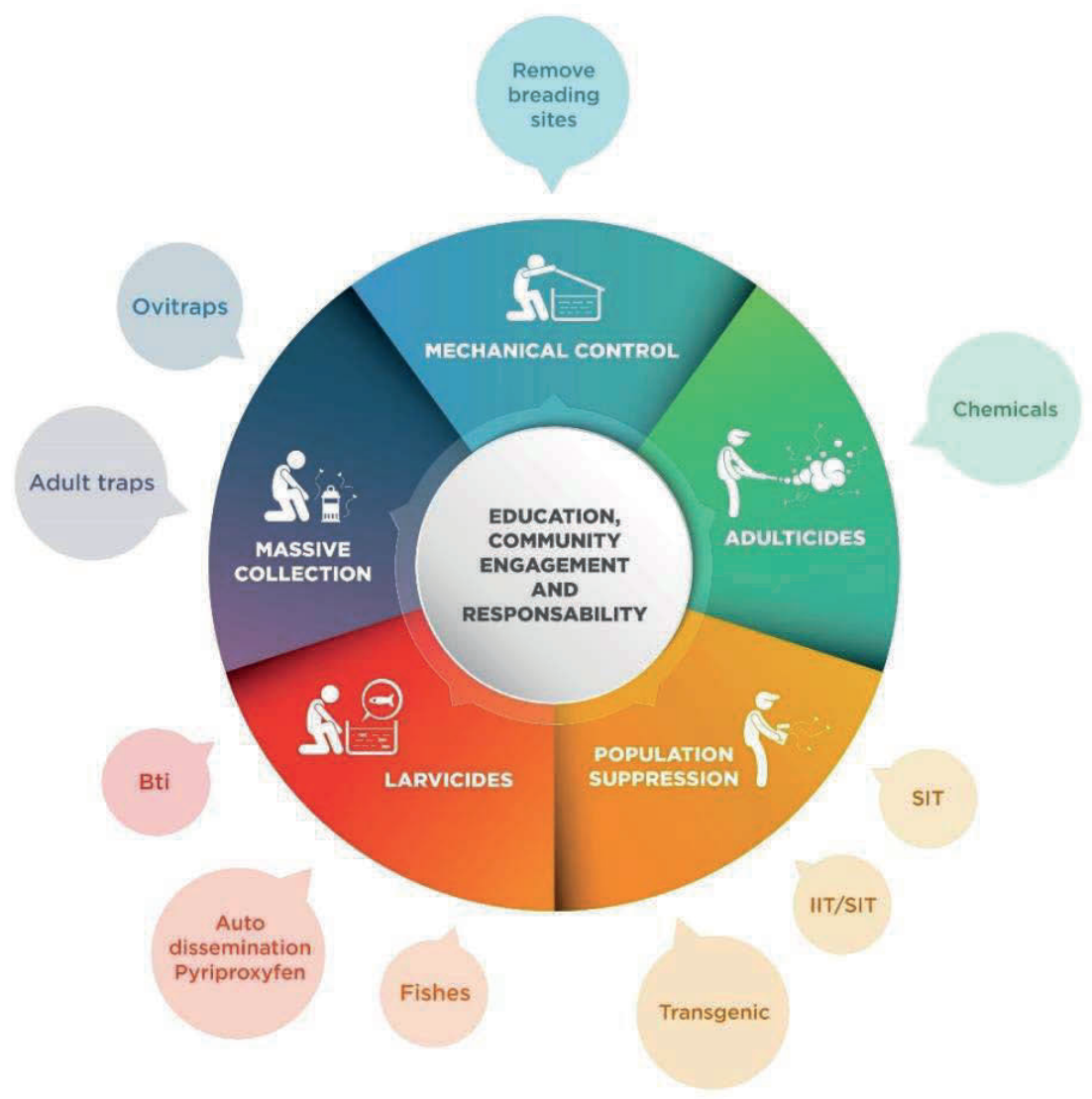

Figure 1. Integrated control programme for Aedes aegypti populations in Brazil.

The distribution and incidence of vector-borne diseases are determined by ecological factors, but they are also influenced by the behaviour of humans. Thus, vector control interventions that incorporate human population engagement are more likely to be successful as they offer the opportunity to take into account community problems (Townson et al. 2005).

The WHO has prepared and made available guidelines to assist national programmes with the design and implementation of social mobilization and communication strategies aimed at dengue fever prevention and control. The approaches to social mobilization are known by the initials "COMBI" (Communication-for-Behavioural-Impact) that integrate the participation of different members of the community, from households to political leaders. COMBI represents a set of marketing, education, communication, promotion, advocacy and mobilization approaches with the same goal, i.e. to ensure sustained community participation to combat Ae. aegypti and as such, to promote the health of community members (Parks and Lloyd 2004; Tapia-Conyer et al. 2012). 


\subsection{The Brazilian Perspective}

In Brazil, the Municipal Health Secretariats have begun to manage and execute PNCD actions with the support of the States and the Ministry of Health, with most funding provided at the federal level. Engagement of the communities and education of the public in the control of Ae. aegypti does not mean to bombard people with information about mosquitoes or vector-borne diseases. In Brazil, it has happened that despite growing levels of public knowledge about mosquitoes and their control, many people are not taking the required basic actions such as the elimination of larval sources (Claro et al. 2006). Nevertheless, a study conducted in Ribeirão Petro (southeastern Brazil) reveals the relevance of educational campaigns and educational health programmes using different types of media to reach different community levels to transmit the necessary information (Alves et al. 2016).

Caprara et al. (2015) developed an eco-health programme, based on community engagement, developing and distributing educational and informative material. They also promoted workshops for the community and developed activities to involve the community directly, such as mobilization of schoolchildren and the elderly, organization of meetings and active participation during campaigns to remove/relocate breeding sites. Although the overall result shows that there was still an increase in the mosquito population after the rainy season (which also corresponded to the end of the experiment), the non-treated site had a significantly higher increase in mosquito density compared to the treated area during the same period (Caprara et al. 2015).

The key to educational campaigns is achieving a long-term modification of the behavioural of the general public that must be conscious of its own actions and be responsible for the surrounding environment. In support, a recent Brazilian sanitary legislation allows the application of fines in the case of impediment or difficulty when implementing sanitary measures that aim at the prevention of the diseases and their dissemination (Brasil 2016).

\subsection{Innovations and Experiences of Other Countries}

Community engagement and information activities were performed in Brazil during the entire mosquito population suppression Projeto Aedes Transgênico (2010-2013 described in Section 7) that relied on the release of genetically modified mosquitoes (GMM) (Capurro et al. 2016). These activities, carried out before and during the mosquito release project, showed positive results and provided guidance for the design of similar public engagement plans in other regions or countries. This pioneering study in continental America showed that full transparency was crucial to make the public aware of all aspects of the mosquito release project, particularly in this case involving genetically modified organisms.

The work from Sommerfeld and Kroeger (2015) reviews community-based vector control interventions in different countries in Latin America that are fighting against dengue and using educational campaigns, chemical and non-chemical strategies, including new approaches such as waste management. The authors mention that these strategies involving the community require establishment of a 
prolonged interaction with control services, municipalities and other public actors, proving to be rewarding during the process and with excellent potentials for sustainability, however, they were time-consuming and costly at the beginning. The results of community participation programmes used in Mexico showed that continuity of these activities in long-term campaigns is a prerequisite to achieve the desired goals (Tapia-Conyer et al. 2012). However, governments are often reluctant to invest and support these initiatives, and consequently, these programmes are often relegated to serve as epidemiological projects during dengue outbreaks.

\section{MECHANICAL CONTROL}

\subsection{General Overview}

In general, mechanical control consists of the elimination of Ae. aegypti larval breeding sites from domestic and peridomestic areas, and the application of measures that prevent the contact between humans and the vector. The interventions include changing the environment through cleaning and removal of possible habitats suitable for any stage of Ae. aegypti and Ae. albopictus to prevent or minimize vector propagation. This entails covering water storage containers, disposing of nonbiodegradable waste, and installing mosquito screens on windows, doors and other entry points, in addition to the use of mosquito bed nets. Local government agencies must take responsibility for the clean-up of public spaces and to eliminate illegal dumps and discarded tyres (Arunachalam et al. 2012; US-EPA 2017; WHO 2017e).

\subsection{The Brazilian Perspective}

Dengue is a disease that has ecological, biological and social factors involved in its transmission. The dynamics of Ae aegypti breeding sites are closely linked to human behaviour; therefore, elimination of larval sites through household interventions is an efficient way to reduce the mosquito population. In Brazil, the removal of breeding sites is the responsibility of households. Periodically the community health agents, and the 'Endemic Disease Control Agents' (EDCA) visit houses looking for possible breeding sites, but they are mainly responsible for non-residential properties, and if necessary, integrate chemical (insecticide) application (Zara et al. 2016).

Chaebo and Medeiros (2017) investigated five conditions for an effective strategy for dengue control policy implementation through co-production, which they defined as the strategy for policy implementation resulting from technological, economic, and institutional influences. Initially the technical, economic, normative, cognitive and structural conditions were analysed and as a result they stated that technical, economic and normative conditions are interdependent, and changing one will change the others. In addition, the authors added two extra conditions to implement policy using co-production that they defined as cognitive and structural conditions. Including these conditions to the main study, the authors state:

\footnotetext{
"We believe, it is impossible to successfully undertake policy implementation via coproduction unless users recognize that an important problem exists and are able and willing to undertake the necessary co-production actions" (Chaebo and Medeiros 2017).
} 
Unfortunately, besides the responsibilities of authorities, the communities often wait for the public vector control services to carry out the task of controlling mosquito breeding sites. In some cases, communities are fully aware of the threats leaving breeding sites and their responsibility to eliminate them, but they are not involved in the programme, and this paradigm needs to change. In integrated vector control, the householders must be stimulated to interact with vector control staff and to ensure appropriate interpersonal communication (Arunachalam et al. 2010).

\subsection{Innovations and Experiences of Other Countries}

The effect of encouraging community members to eliminate Ae. aegypti breeding sites showed a favourable impact in studies carried out in the Caribbean (Rosenbaum et al. 1995), Latin America (Tapia-Conyer et al. 2012), Thailand (Suwannapong et al. 2014), Pakistan (Zahir 2016), USA (Healy et al. 2014), and many other parts of the world (Spiegel et al. 2002; Kay and Nam 2005; Vanlerberghe et al. 2009; Sanchez et al. 2012). There is a consensus among health authorities that this measure is an essential component of environmentally sustainable mosquito control programmes. A recent mathematical model for dengue control developed by Carvalho et al. (2019) confirms that, even though the combination of mechanical and chemical approaches is the most suitable one instead of using them separately, it is still insufficient to eliminate disease transmission completely.

\section{MASS-TRAPPING}

\subsection{General Overview}

Different models of traps are available to monitor Ae. aegypti and Ae. albopictus populations, and they can generate baseline data that are essential to guide control operations. They can also be included in the entomological surveillance to improve mosquito population density prediction prior to epidemic periods (Honório et al. 2009; Degener et al. 2014). An increased number of deployed traps can be used to reduce the target mosquito population, i.e. the gravid females are attracted to the oviposition traps (ovitrap) and are killed when making contact with the oviposition substrate that is impregnated with insecticides, or lethal ovitraps, collecting eggs that are subsequently killed by an insecticide-treated ovistrip (Paz-Soldan et al. 2016).

According to a review on mass-trapping interventions for suppression of urban Aedes by Johnson et al. (2017), successful deployment is achieved with a high area coverage $(>80 \%)$, a pre-intervention and/or additional source reduction, the direct involvement of community members for sustainability, and the use of newgeneration traps (such as the Autocidal Gravid Ovitrap - AGO, or Gravid Aedes Trap - GAT) to outcompete remaining water-holding containers.

In areas where Ae. albopictus co-exists with Ae. aegypti, eggs or larvae collected in ovitraps need to be taken to the laboratory for species identification at the larval stage or maintained until adult emergence. In those areas, the AGO is a good alternative to monitor mosquito populations (Caputo et al. 2015). These traps are 
simple, specific and efficient for gravid females, and their integration with other chemical or biological control methodologies can contribute significantly to decrease mosquito populations. However, their use is laborious, which is a disadvantage for deployment over large areas of action. Combining mass-trapping of adults, with the use of larvicides, can have a more significant impact on Ae. aegypti populations than using each of these methods alone (Regis et al. 2008).

\subsection{The Brazilian Perspective}

Mass-trapping is not currently used for mosquito control in any vector control programme in the country; however, several works have assessed the effect of lethal ovitraps, and the results were promising in several situations (Regis et al. 2008, 2013). A modified ovitrap containing Bacillus thuringiensis israelensis (Bti - see next Section) that kills any larvae developing inside was evaluated in north-eastern Brazil. The Bti-treated trap can safely remain in the field for up to two months and during that time can collect more than 7000 eggs/trap (Regis et al. 2008), of course depending on the initial population density.

Deployment in urban areas of ovitraps treated with the pyrethroid deltamethrin reduced the density of the adult female population by $40 \%$ (Perich et al. 2003). The study involved the placement of 10 ovitraps/residence (five inside and five outside) for 12 weeks in two municipalities in Rio de Janeiro, and the sampling of 30 houses per intervention neighbourhood. The authors mentioned that although lethal ovitraps were not designed to be a control method to be used alone, their results show that lethal ovitraps could provide an inexpensive, simple, environmentally benign way to be integrated into vector control strategies (Perich et al. 2003).

Sticky ovitraps with an adhesive strip, rather than an insecticide-treated oviposition surface that traps the ovipositing females when they land, have been used for surveillance in areas with high mosquito insecticide resistance. A study was conducted for 17 months to suppress mosquito populations in the Amazon region through a mass-trapping system using sticky ovitraps. The authors conclude that this intervention alone was not able to show mosquito population suppression, and they indicate as probable reasons a lack of buffer zones, which allowed mosquito migration from other areas, the lack of an area-wide approach due to the small size of the treated area, and insufficient collection efficacy of the trap or inadequate number of traps/household (Degener et al. 2015).

\subsection{Innovations and Experiences of Other Countries}

Like the Brazilian experience, Ae. aegypti populations were significantly reduced in Thailand when lethal permethrin-treated ovitraps were deployed in conjunction with other interventions such as source reduction, use of screen covers, and biological control. In this case, they also evaluated the impact on dengue transmission and the proportion of DENV IgG-IgM positives in the treated areas, which were reduced from $13.46 \%$ to $0 \%$, whereas those from untreated areas increased from 9.43 to $19.15 \%$ (Kittayapong et al. 2008). 
A previous study using lethal ovitraps, also in Thailand, showed a $49-80 \%$ reduction in the mosquito population in an experiment over 30 weeks (Sithiprasasna et al. 2003). In Cairns, Australia, the acceptance by households of a mass-trapping scheme allowed the comparison of different types of lethal ovitraps in three separate trials. The results suggest that a high trap density can collapse a mosquito population over time (Ritchie et al. 2009).

The AGO, baited with an attractant and containing an adhesive card placed inside the trap entrance that serves as an autocidal oviposition substrate, was developed by the Centers for Disease Control and Prevention (CDC) to catch gravid Ae. aegypti females (Mackay et al. 2013). The AGOs placed in $85 \%$ of residences in four communities of two municipalities in Puerto Rico between November 2015 and February 2016 to control Ae. aegypti mosquitoes significantly reduced the prevalence of CHIKV IgG antibodies in participating communities without any other control tactic used (Lorenzi et al. 2016).

\section{LARVAL CONTROL}

\subsection{General Overview}

Larvicides are biocides used against immature mosquito stages and their use fits well within environment-friendly management strategies (except in emergency situations). Larval control can minimize the need for widespread use of insecticides to kill adult mosquitoes. Larvicides are used by vector control staff to treat waterholding structures and containers in public places, whereas the general citizen is supposed to do the same to treat fountains, septic tanks, pots and pools on private properties. The use of larvicides should be restricted to containers that are not used for drinking, and that cannot be covered, dumped or removed (CDC 2017a). Widely used is $B t i$, a bacterium marketed commercially as a biological larvicide to control insects relevant to public health. It is safe for humans, but when ingested by mosquito larvae, lethal endotoxins proteins are produced during the bacterium sporulation, killing the larvae before reaching adulthood (Federici et al. 2007; Ibrahim et al. 2010). An alternative is the auto-dissemination approach, that can be augmented by the release of males which were tainted with pyriproxyfen, a juvenile hormone analogue, and who will contaminate females during mating or directly the larval habitats (Bouyer and Lefrançois 2014).

\subsection{The Brazilian Perspective}

In Brazil, Bti is used since 2002 when resistance to the organophosphate larvicide, temephos, was observed (Suter et al. 2017). In those cases, Bti can be used alone or in association with different chemical larvicides such as pyriproxyfen (MS/FNS 2009; Suter et al. 2017). Recent bioassays with Brazilian populations of Ae. aegypti and Ae. albopictus that have been exposed for many years to insecticides, in particular $B t i$, showed that both species are equally susceptible to Bti, suggesting that the same application rates may be used where the species co-exist (Suter et al. 2017). 
A study in Manaus (northern Brazil), using pyriproxyfen, showed not only mosquito mortality, but also that adult emergence was reduced more than 10 times (Abad-Franch et al. 2015). They concluded that this approach is very promising to complement current mosquito control strategies, which heavily rely on the difficult task of detecting vector breeding sites and therefore perform poorly.

In some contexts, however, the application of larvicides by public health services can be complicated. Many Aedes breeding sites are small, sheltered and difficult to locate (cryptic habitats). Therefore, depending entirely on breeding site treatment or removal is complex, requiring a combined strategy. Therefore, auto-dissemination methods are an alternative to overcome these limitations, as they rely on the oviposition behaviour of adult mosquitoes and their attraction to breeding sites. The auto-dissemination method to control Aedes mosquitoes requires artificial adult resting sites (dissemination stations) to which adult females are attracted and where they are contaminated with pyriproxyfen when entering the station and then contaminate breeding sites with lethal levels of pyriproxyfen (Caputo et al. 2012; Unlu et al. 2017).

\subsection{Innovations and Experiences of Other Countries}

In a study carried out in Thailand, about $61.8 \%$ of water containers were treated with $B t i$ and temephos, and the rate of positive containers (with larvae) was reduced from $13.8 \%$ in untreated areas to $3.7 \%$ in treated areas $(\mathrm{P}<0.001)$ showing the combined approach of $B t i$ and insecticide were effective in achieving the result in the target area (Arunachalam et al. 2010).

The autodissemination approach was tested in the USA with pyriproxyfen-treated males and showed, in combination with another insecticide, a decline in the $A e$. albopictus adult population by around $74-78 \%$ (Unlu et al. 2018). In a similar approach using only pyriproxyfen, the male mosquitoes were shown to be vehicles of insecticide in areas with low mosquito densities to intoxicate potential breeding sites before the seasonal emergence of the target population (Mains et al. 2015). These males can also contaminate the females, increasing even more the affected breeding sites, interrupting the development of immature offspring. On the other hand, a study only using pyriproxyfen conducted in Florida showed that there was no apparent pupal mortality during the study period (Lloyd et al. 2017).

In Southeast Asia, larvivorous fish, e.g. from the genus Gambusia, that feed on mosquito larvae are often used in pots that decorate houses and terraces (Araújo et al. 2015) (Fig. 2). This practice is also employed as a non-insecticidal method to control malaria vectors in India and Africa (Kamareddine 2012; Kant et al. 2013; Walshe et al. 2013). However, the use of fish to control mosquito larvae is feasible and effective only in breeding sites that are easily identified and in those as observed in Asian culture (Chandra et al. 2008).

Studies carried out in Mexico have shown that larvivorous fish can reduce larval and pupal numbers in household water containers, but there was no evidence of a reduction in DENV infection (Morales-Pérez et al. 2017). In villages of Karnataka, South India, the introduction of fish, e.g. the guppy Poecilia reticulata (Peters) and Gambusia affinis (Baird \& Girard), combined with information, education and 
communication campaigns, had a significant impact on the density of the Aedes population and decreased the prevalence of chikungunya (Ghosh et al. 2011). This method is harmless to humans and exhibits minimal risks of mosquito resistance. Besides, the fish are cheap to produce in most cases, saving resources that could serve for other needs. However, in some cases, these invasive fish can be negative effects on biodiversity (El-Sabaawi et al. 2016).

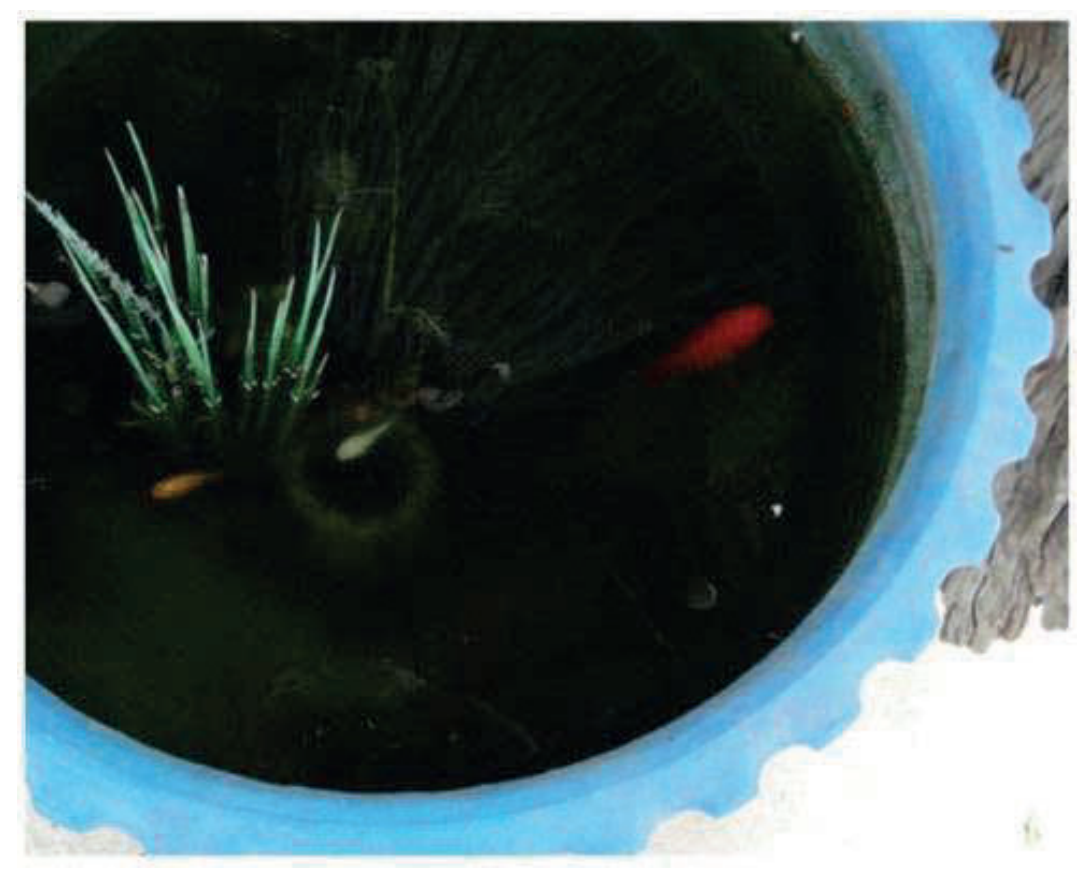

Figure 2. Larvivorous fish in water containers in Southeast Asia (Araújo et al. 2015).

\section{ADULT CONTROL}

\subsection{General Overview}

Adulticides are intended to impact a significant number of infected adult mosquitoes in a short time through surface (indoor) and/or spatial (outdoor) treatments with insecticides of residual or low residual activity. The indoor residual spraying (IRS) consists of the application of long-acting chemical insecticides on the walls or others surfaces of houses in a given area using backpack sprayers. A recent review using seven databases evaluated the effectiveness of indoor spraying of insecticides and showed the effect on adult mosquitoes is high immediately after application (Samuel et al. 2017). These spraying activities are usually carried out by staff of the vector control programmes, but the general public can also buy commercial adulticides for use in their homes. 
Space spraying is recommended only in emergency situations when people in a large area are at risk of infection, or mosquito densities are very high. The insecticides can be applied by backpack sprayers, trucks or airplanes. When cases of the disease are detected in the early stages of an epidemic, emergency space spraying can reduce disease transmission quickly. However, applying other vector control measures such as larviciding or environmental modification help provide longer-term control as a part of an integrated mosquito management programme (CDC 2017b; MS 2017a; WHO 2017b, 2017f).

\subsection{The Brazilian Perspective}

In 2016, the Brazilian Government published law No. 13.301 of July 27, 2016 that allows the incorporation of adult vector control mechanisms through aerial spraying upon approval of sanitary authorities and scientific evidence on the efficacy of the measure (MS 2017b). However, in the same year, the Oswaldo Cruz Foundation (FIOCRUZ) issued a technical note stating that there are risks to human health related to the spraying of a neurotoxic product such as malathion in urban areas. They considered that it not only posed a threat to the environment and the population's health, but it is also of little efficacy in the combat of Ae. aegypti, which in its adult stage lives mainly within the domiciles (FIOCRUZ 2016).

\subsection{Innovations and Experiences of Other Countries}

The Florida Keys Mosquito Control District used aerial sprays with insecticide (naled) and bacterial larvicides to reduce Ae. aegypti populations in urban areas of Key West, Florida, USA (CDC 2017c; Pruszynski et al. 2017). The aerial applications of Bti caused a significant decrease in adult female populations throughout the summer because, in Key West, larvae of this mosquito develop in micro-containers around human habitations. The advantage of aerial spraying of larvicide is the area-wide coverage over and around urban areas achieved in a short period and in the case of Key West, the aerial application of larvicide was effective in controlling the Ae. aegypti outbreak (Pruszynski et al. 2017).

\section{POPULATION SUPPRESSION INTEGRATING THE STERILE INSECT TECHNIQUE, THE INCOMPATIBLE INSECT TECHNIQUE, AND GENETICALLY MODIFIED MOSQUITOES}

To improve the Brazilian dengue vector control programme, it is mandatory to use the principles of IVM to minimise financial and personnel requirements and be able to cover the target geographic area to be treated with the chosen vector control methods. Furthermore, improved monitoring and evaluation tools for vector control should be developed and applied, and relevant training must be performed based on necessity (Horstick et al. 2010).

As described above, suppression of disease-transmitting mosquito populations is still mainly based on insecticides (larvicides and adulticides). A reduction in 
mosquito densities is the most reliable method to decrease pathogen-host contact, which will reduce the probability of humans becoming infected. Nevertheless, the long-term use of chemical compounds has selected for mosquito populations resistant to them, resulting in the increase of the number of cases in endemic areas and the spread of diseases transmitted by these insects into entirely new areas (Campos et al. 2015; Díaz et al. 2015; Zanluca et al. 2015; Luksic et al. 2017).

Other population suppression approaches are therefore under development and evaluation, and these could be integrated into the currently used IVM approaches. These methods have the benefit that they can reduce vector populations in a target area, without causing the selection of resistance as promoted by insecticides (Bourtzis et al. 2016). They have in common the release of sterilized male insects (because male mosquitoes do not blood-feed and therefore do not transmit diseases), and the monitoring of the sterile and wild male populations in the target area (Lees et al. 2014). These males must be mass-reared to achieve the required numbers to promote suppression of the target population. After release, an efficient monitoring system is needed to be able to follow the vector population fluctuation and if required, to adjust male production and release rates (Hood-Nowotny et al. 2006; Vreysen 2021).

The first of these approaches is the Sterile Insect Technique (SIT), which uses an ionizing radiation source (gamma or X-ray) to sterilize the mass-reared males that will be released into the open field in numbers 10-100 times larger than the wild-type population. The high sterile to wild male overflooding ratios increase the probability of a mating of a wild virgin female with a sterile male (Vreysen et al. 2014; Dyck et al. 2021). For more than 50 years, the SIT has proven to be an effective control tactic to suppress agricultural insect pests such as moths, fruit flies, screwworm and tsetse flies (Hendrichs and Robinson 2009; Klassen et al. 2021). With support from the international scientific community through the International Atomic Energy Agency (IAEA) and the Food and Agricultural Organization of the United Nations (FAO), several countries like Brazil, Cuba, Italy, France (La Réunion), Mauritius, Mexico, Thailand, USA and others have or are initiating pilot trials against mosquitoes on a small to medium scale as a proof-of-concept (Lees et al. 2021).

A similar approach is the release of males that are infected with symbionts that cause sterility without the use of ionizing radiation. The intracellular bacterium, Wolbachia, is a symbiont that is sexually transmitted and maternally inherited and can promote cytoplasmic incompatibility in embryos when the father is infected with a particular strain but not the mother (Sinkins 2004). This approach is called the Incompatible Insect Technique (IIT) (Zabalou et al. 2009) and is already under evaluation in several countries like USA (Mains et al. 2016), China, and in French Polynesia for Aedes polynesiensis (O'Connor et al. 2012). A related approach under evaluation in Australia, Brazil (Niteroi and Rio de Janeiro), Colombia (Bello and Medellín), and Indonesia (Yogyakarta) through the Eliminate Dengue and other campaigns (De Barro et al. 2011; Maciel-de-Freitas et al. 2012; Flores and O'Neill 2018) involves the release of both Wolbachia-infected males and females, resulting in population replacement by substituting the original population with a Wolbachiainfected population, this approach takes advantage of Wolbachia's capacity to block pathogen transmission to the human host (Van den Hurk et al. 2012; Frentiu et al. 2014; Dutra et al. 2016). 
The release of genetically modified mosquitoes (GMM) is the third population suppression alternative that is under evaluation, and so far, some programmes or trials have demonstrated success in reducing the mosquito population in the target areas Carvalho et al. (2015). This transgenic approach, which requires regulatory approvals and involves other issues, has a broad range of possibilities to interfere and trigger mosquito population suppression or population replacement by blocking disease transmission, due to its potential to manipulate, exclude or include new features at the genomic level of the target mosquito species (Handler 2002; Travanty et al. 2004; Catteruccia et al. 2009).

Brazil is one of the best locations to test and evaluate these new technologies, due to its diverse environments and extensive prevalence of arboviruses. Since 2002, Brazil has been implementing the PNCD to control dengue transmission and related diseases, such as chikungunya, Zika, and yellow fever. However, the efforts and strategies that are combined in the PNCD cannot entirely prevent disease dissemination; on the contrary, the number of reported cases only increases every year (Pessanha et al. 2009; SS-PE 2015; MS 2017c). Therefore, the inclusion of new technologies cannot alone change the vector density and transmission situation if their deployment is not carefully planned according to the specific characteristics and needs of each target area and taking advantage of the best characteristic of each of the technologies. Thus, it is necessary to combine and better apply where appropriate all these techniques as part of effective IVM approaches (Horstick et al. 2010; Bourtzis et al. 2016; Van den Berg et al. 2012).

\subsection{Two-step Male Release Strategy - Integration of Techniques}

Several models on the use of these inovative technologies, such as GMM, the IIT, the SIT and others, predict that it will take several seasons to suppress a targetted mosquito population, and even when achieving it, some virus transmission can still occur (Andraud et al. 2012; Chen and Hsieh 2012; Okamoto et al. 2013; Ndii et al. 2015). The IVM approaches can be improved by applying the suppression methods more effectively and based on mosquito biology. Models combining several techniques demonstrate the advantages of targeting different developmental stages and integrating different ways to suppress a population.

A two-step strategy was proposed to reduce mosquito populations and then block efficiently disease transmission (Carvalho et al. 2014). A first step involves the integration of any methods which have a significant impact decreasing the target vector population, such as the use of larvicides and adulticides, educational campaigns, breeding site elimination, the release of sterile males, which also can be carrying pyriproxyfen to suppress a population. Once the population has been suppressed, this should be followed by a second step, which could involve releases targeting population substitution (for example Wolbachia-infected females or GMM), in order to disrupt disease transmission entirely. The idea is first to reduce the mosquito population to extremely low levels, and then to substitute this residual population by one that is no longer able to transmit viruses, thereby obtaining the advantage of this low-cost combination strategy that can be implemented as part of IVM over larger areas (Fig. 3). 


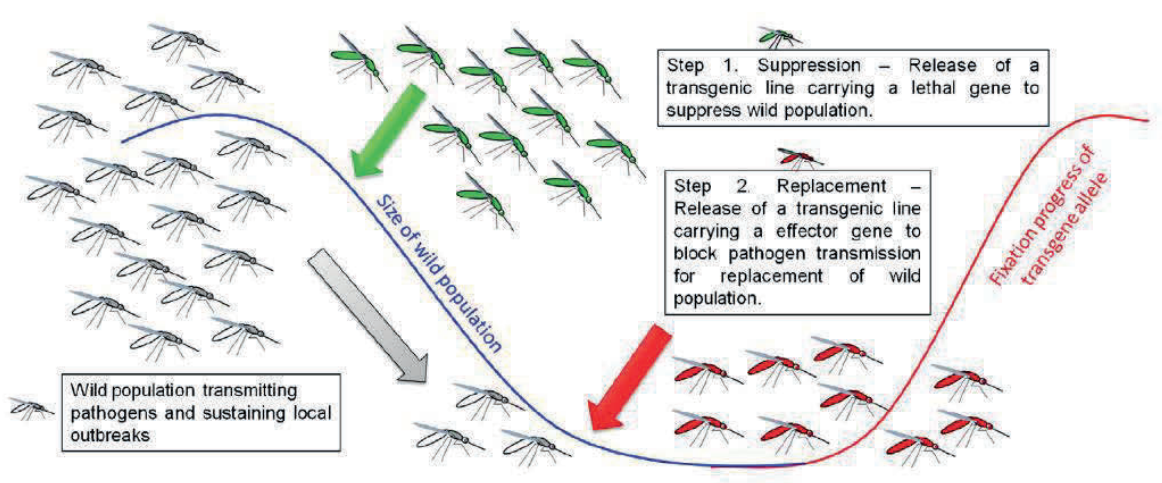

Figure 3. A schematic diagram of two-step male release strategy (Carvalho et al. 2014) using as an example a genetically modified mosquito (GMM) strain for population suppression and replacement.

Recently, some studies proposed transgenic constructions able to block the virus transmission with low impact on the overall mosquito fitness (Jupatanakul et al. 2017; Buchman et al. 2019). Strategies using RNA interference or RNA-based strategies targeting critical virus RNA's were already developed and tested under laboratory conditions and their fitness evaluated (Franz et al. 2006, 2014; Buchman et al. 2019). In addition, other strains targeting malaria parasites have also been developed for population replacement, entirely blocking the parasite transmission (Kokoza et al. 2010).

Nevertheless, it is a common evolutionary fact that without a stable gene drive mechanism such systems alone may not be enough to replace the population successfully, and over time will be displaced (James 2005). However, the use of new gene editing techniques, such as CRISPR-Cas9, provide an easier way not only to create strains for population suppression, but also for population replacement (Häcker and Schetelig, this volume). They may also eventually overcome the issue of gene drive resistance mechanisms that emerge in field populations (Champer et al. 2018). This resistance can originate from the drive itself, when cleavage is repaired and it changes the sequence of the target site, so that it can no longer be recognized, becoming resistant to future conversion.

A model provides that more than 100 generations are needed for the wild-type population to reach $50 \%$ of resistant alleles and the use of CRISPR-Cas9 can be an efficient way to provide stable strains for vector control programmes without the accumulation of genetical instability (Unckless et al. 2017). It is a matter of time for the availability and developing state of art of the gene drive technologies to provide further information on their behaviour in the genome and their ecological impact and long-term effects.

Further discussion among the scientific community, stakeholders and population regarding the advantages, risk assessment, and regulatory issues of using them are needed (Carter and Friedman 2016; Häcker and Schetelig, this volume; Nielsen, this volume). 


\subsection{Open Field Release Using the OX513A Ae. aegypti Transgenic Line and its Evaluation}

Brazil and other countries have initiated the field assessment of the impact of some of these new technologies as part of IVM approaches. The first continental GMM release to suppress an Ae. aegypti mosquito population was carried out between 2011 to 2015 in two different cities, Juazeiro and Jacobina in the state of Bahia, in northeastern Brazil. This Projeto Aedes Transgênico aimed at evaluating various aspects of a full IVM programme by using the OX513A transgenic line developed by the commercial company Oxitec Ltd. (Lee et al. 2009). Before the release of the genetically modified male mosquitoes in Brazil, several regulatory steps, as described by Carvalho and Capurro (2015), had to be performed. The most crucial approval was provided by the Brazilian National Committee of Biosafety, which regulates all research projects and products directly and indirectly involving genetically modified organisms, including a public review of the project that had no vote against it.

Due to all apprehensions around genetically modified organisms in plants and other organisms, the Projeto Aedes Transgênico initiated a pioneering communication plan to create adequate public awareness regarding the use of this technology and its purpose. Emphasis was likewise placed on community engagement and stakeholder participation during the execution of the project. This experience can serve as a model for other initiatives using the same approach (Carvalho et al. 2015; Capurro et al. 2016).

In the initial phase, some quality parameters of these GMM males were assessed in the target area/environment, such as flight range and longevity under field conditions. Based on this first phase, an assessment was made of the number of sterile male mosquitoes to be released to achieve population suppression, and the data compared with those of the first trial in Grand Cayman Island (Harris et al. 2011, 2012). This range-finding process, consisting of six weeks of releases and the three following weeks for evaluation (around $2800 \mathrm{males} / \mathrm{ha} / \mathrm{week}$ were released in this first phase), was helpful in optimizing the release number and mass-rearing process. It was also crucial for the next phase involving overflooding the target area in Juazeiro with male mosquitoes for suppression purposes because it provided and confirmed parameters to initiate this suppression phase (Carvalho et al. 2015).

After the 17 months release period, around $95 \%$ of population suppression was achieved in Juazeiro, based on an indirect evaluation using a monitoring system with ovitraps. Afterwards, the study kept track of the GMM and wild-type populations after the suppression effect. The outcome was that when the releases were discontinued, the wild mosquito population returned rapidly to pre-control levels within 17 weeks due to immigration and other factors, such the eclosion of eggs that remained unhatched during the release phase (Garziera et al. 2017).

The second part of Projeto Aedes Transgênico included procedures for ground shipment of pupae to the city of Jacobina, around $300 \mathrm{~km}$ from the mass-rearing facility. This step also included optimizing the monitoring system, increased community engagement and awareness activities, and improved efficiency of massrearing procedures and release methods. The Projeto Aedes Transgênico was terminated at the end of the contract with the Bahia State Health Department. Again, 
genetic monitoring of the GMM and wild-type populations continued postsuppression, indicating that portions of the transgenic strain genome became incorporated into the target population (Evans et al. 2019).

In parallel, as an independent initiative, Oxitec started a trial in Piracicaba and Juiz de Fora municipalities (in São Paulo state, south-eastern Brazil), following a similar approach and using the predetermined parameters established during the first two initials trials in the country (Paes de Andrade et al. 2016). So far these trials are service contracts directly performed with the municipalities without any support of the Brazilian Ministry of Health.

\section{FINAL CONSIDERATIONS}

Numerous activities are currently being integrated in Brazil to suppress Ae. aegypti, the vector of various arboviruses. Box 1 presents some important bullets summarizing the strengths, weaknesses, opportunities, and threats (SWOT) for the Brazilian vector control strategy.

Box 1. Strengths, weaknesses, opportunities, and threats of the Brazilian vector control strategy.

\begin{tabular}{|c|c|}
\hline STRENGTHS & WEAKNESSES \\
\hline $\begin{array}{l}\text { - } \quad \text { Strong research institutions } \\
\text { - } \quad \text { Decentralisation of the vector control } \\
\text { - } \quad \text { Denistence of the National Plan for } \\
\text { - } \quad \text { Historical record of successful vector } \\
\text { elimination } \\
\text { - Reference research laboratories }\end{array}$ & $\begin{array}{l}\text { - Insufficient budget / trained staff } \\
\text { - Insufficient public mobilization } \\
\text { resulting in low community } \\
\text { commitment and household } \\
\text { participation and acceptance } \\
\text { - Limited time required for data } \\
\text { analysis resulting in poor } \\
\text { management } \\
\text { - Lack of consistent and frequent } \\
\text { control strategy application }\end{array}$ \\
\hline OPPORTUNITIES & THREATS \\
\hline $\begin{array}{l}\text { Possibility to test new techniques in } \\
\text { different biomes and urbanization levels } \\
\text { Use of different combinations and } \\
\text { methods for vector control for specific } \\
\text { conditions } \\
\text { Learning from different models and } \\
\text { previous experiences (including other } \\
\text { countries) }\end{array}$ & $\begin{array}{l}\text { - The continuous increase in reported } \\
\text { arboviruses cases } \\
\text { - Different vector species participating } \\
\text { in disease transmission } \\
\text { - Entry of new arboviruses promoting } \\
\text { illness } \\
\text { - Difficulty of treating increasing cases } \\
\text { in big cities }\end{array}$ \\
\hline
\end{tabular}


PNCD activities and efforts are not enough to interfere with disease transmission by this vector. All have been recommended by WHO (Brasil 2009), however they have to be adapted to different levels of difficulty in different situations (for example, vector control in isolated small areas vs non-isolated, large and densely populated urban areas). Among the main reasons for the insufficient control are the low budget, lack of trained staff, insufficient insecticide application, insufficient public mobilization, and poor management. There is a need to increase vector control efforts all over the country, but at the same time to complement the adopted strategies with promising innovative approaches (Zara et al. 2016; Coelho 2012). There is the potential to exploit and include new methods as part of the IVM package in order to suppress more effectively and sustainably the mosquito populations and control disease transmission.

The current PNCD activities being performed should not be interrupted due to the advent of new technologies, but these can be validated and implemented as part of the IVM package. The range of approaches integrating new technologies is huge, and they have demonstrated that they can successfully contribute to mosquito population suppression and reduce disease transmission. In view of the proof-of-concept of these techniques (most of them carried out under Brazilian conditions), they are ready for the next step, which is their application as part of a long-term programme, not only to demonstrate their effect on mosquito populations, but also their impact on disease transmission.

\section{REFERENCES}

Abad-Franch, F., E. Zamora-Perea, G. Ferraz, S. D. Padilla-Torres, and S. L. B. Luz. 2015. Mosquito-disseminated pyriproxyfen yields high breeding-site coverage and boosts juvenile mosquito mortality at the neighborhood scale. PLoS Neglected Tropical Diseases 9 (4): e0003702.

Alves, A. C., A. L. dal Fabbro, A. D. Costa Passos, A. F. T. Mendes Carneiro, T. Martins Jorge, and E. Zangiacomi Martinez. 2016. Knowledge and practices related to dengue and its vector: A community-based study from southeast Brazil. Revista da Sociedade Brasileira de Medicina Tropical 49 (2): $222-226$.

Andraud, M., N. Hens, C. Marais, and P. Beutels. 2012. Dynamic epidemiological models for dengue transmission: A systematic review of structural approaches. PLoS One 7: e49085.

Araújo, H. R. C., D. Carvalho, R. Ioshino, A. Costa-da-Silva, and M. Capurro. 2015. Aedes aegypti control strategies in Brazil: Incorporation of new technologies to overcome the persistence of dengue epidemics. Insects 6: 576-594.

Araújo, V. E. M., J. M. T. Bezerra, F. F. Amâncio, V. M. de A. Passos, and M. Carneiro. 2017. Aumento da carga de dengue no Brasil e unidades federadas, 2000 e 2015: Análise do Global Burden of Disease Study 2015. Revista Brasileira de Epidemiologia 20 (Suppl. 1): 205-216.

Arunachalam, N., S. Tana, F. Espino, P. Kittayapong, W. Abeyewickreme, K. T. Wai, B. K. Tyagi, A. Kroeger, J. Sommerfeld, and M. Petzold. 2010. Eco-bio-social determinants of dengue vector breeding: A multicountry study in urban and periurban Asia. Bulletin of the World Health Organization 88: 173-184.

Arunachalam, N., B. K. Tyagi, M. Samuel, R. Krishnamoorthi, R. Manavalan, S. C. Tewari, V Ashokkumar, A. Kroeger, J. Sommerfeld, and M. Petzold. 2012. Community-based control of Aedes aegypti by adoption of eco-health methods in Chennai City, India. Pathogens and Global Health 106: 488-496.

Augusto, L. G. S., A. M. Gurgel, A. M. Costa, F. Diderichsen, F. A. Lacaz, G. Parra-Henao, R. M. Rigotto, R. Nodari, and S. L. Santos. 2016. Aedes aegypti control in Brazil. The Lancet 387: 10521053. 
Bourtzis, K., R. S. Lees, J. Hendrichs, and M. J. B. Vreysen. 2016. More than one rabbit out of the hat: Radiation, transgenic and symbiont-based approaches for sustainable management of mosquito and tsetse fly populations. Acta Tropica 157: 115-130.

Bouyer, J., and T. Lefrançois. 2014. Boosting the Sterile Insect Technique to control mosquitoes. Trends in Parasitology 30(6): 271-273.

Braga, I., and D. Valle. 2007. Aedes aegypti: Histórico do controle no Brasil. Epidemiologia e Serviços de Saúde 16: 113-118.

Brasil. 2009. Diretrizes nacionais para a prevenção e controle de epidemias de dengue. Ministerio da Saude, Secretaria de Vigilância em Saúde, and Departamento de Vigilância Epidemiológica. 1st ed. Série A. Normas e Manuais Técnicos. Brasilia, D. F., Brasil.

Brasil. 2016. Lei No 13.301, de 27 de junho de 2016. Dispõe sobre a adoção de medidas de vigilância em saúde quando verificada situação de iminente perigo à saúde pública pela presença do mosquito transmissor do vírus da dengue, do vírus chikungunya e do vírus da Zika; e altera a Lei no 6.437, de 20 de agosto de 1977. Diário Oficial da União, Brasilia, DF, 28 de junho de 2016. Seção 1, p. 1. ISSN $1677-7042$

Buchman, A., S. Gamez, M. Li, I. Antoshechkin, H.-H. Li, H.-W. Wang, C.-H. Chen, M. J. Klein, J.B. Duchemin, P. N. Paradkar, and O. S. Akbari. 2019. Engineered resistance to Zika virus in transgenic Aedes aegypti expressing a polycistronic cluster of synthetic small RNAs. Proceedings of the National Academy of Sciences of the United States of America 116 (9): 3656-3661.

Campos, G. S., A. C. O. Pinho, C. J. de Freitas, A. C. Bandeira, and S. I. Sardi. 2015. Dengue virus 4 (DENV-4) re-emerges after 30 years in Brazil: Cocirculation of DENV-2, DENV-3, and DENV-4 in Bahia. Japanese Journal of Infectious Diseases 68: 45-49.

Caprara, A., J. W. De Oliveira Lima, A. C. Rocha Peixoto, C. M. Vasconcelos Motta, J. M. Soares Nobre, J. Sommerfeld, and A. Kroeger. 2015. Entomological impact and social participation in dengue control: A cluster randomized trial in Fortaleza, Brazil. Transactions of the Royal Society of Tropical Medicine and Hygiene 109 (2): 99-105.

Capurro, M. L., D. O. Carvalho, L. Garziera, C. Pedrosa, I. Damasceno, I. Lima, B. Duarte, J. Fernandez-Virginio, R. S. Lees, and A. Malavasi. 2016. Description of social aspects surrounding releases of transgenic mosquitoes in Brazil. International Journal of Recent Scientific Research 7: 10363-10369.

Caputo, B., A. Ienco, D. Cianci, M. Pombi, V. Petrarca, A. Baseggio, G. J. Devine, and A. della Torre. 2012. The "auto-dissemination" approach: A novel concept to fight Aedes albopictus in urban areas. PLoS Neglected Tropical Diseases 6(8): e1793.

Caputo, B., A. Ienco, M. Manica, V, Petrarca, R. Rosà, and A. della Torre. 2015. New adhesive traps to monitor urban mosquitoes with a case study to assess the efficacy of insecticide control strategies in temperate areas. Parasites \& Vectors 8: 134.

Carrillo-Hernández, M. Y., J. Ruiz-Saenz, L. Jaimes-Villamizar, S. Y. Gómez-Rangel, and M. Martínez-Gutierrez. 2018. Co-circulation and simultaneous co-infection of dengue, chikungunya, and Zika viruses in patients with febrile syndrome at the Colombian-Venezuelan border. BMC Infectious Diseases 18 (1): 61.

Carter, S. R., and R. M. Friedman. 2016. Policy and regulatory issues for gene drives in insects: Workshop report. J. Craig Venter Institute, San Diego, California, USA. 21 pp.

Carvalho, D. O., and M. L. Capurro. 2015. Community engagement, pp. 409-422. In J. Leonard (ed.), Genetic control of malaria and dengue. Elsevier, Amsterdam, The Netherlands.

Carvalho, D. O., A. L. Costa-da-Silva, R. S. Lees, and M. L. Capurro. 2014. Two step male release strategy using transgenic mosquito lines to control transmission of vector-borne diseases. Acta Tropica 132: $1-8$.

Carvalho, D. O., A. R. McKemey, L. Garziera, R. Lacroix, C. A. Donnelly, L. Alphey, A. Malavasi, and M. L. Capurro. 2015. Suppression of a field population of Aedes aegypti in Brazil by sustained release of transgenic male mosquitoes. PLoS Neglected Tropical Diseases 9: e0003864.

Carvalho, S. A., S. O. da Silva, and I. D. C. Charret. 2019. Mathematical modeling of dengue epidemic: Control methods and vaccination strategies. Theory in Biosciences: 1-17.

Catteruccia, F., A. Crisanti, and E. A. Wimmer. 2009. Transgenic technologies to induce sterility. Malaria Journal 8 (Suppl. 2): S7.

(CDC) Centers for Disease Control and Prevention. 2017a. Integrated Mosquito Management - Zika virus. Atlanta, Georgia, USA. 
(CDC) Centers for Disease Control and Prevention. 2017b. Integrated Mosquito Management for Aedes aegypti and Aedes albopictus mosquitoes. Atlanta, Georgia, USA.

(CDC) Centers for Disease Control and Prevention. 2017c. Information on aerial spraying - Zika virus. Atlanta, Georgia, USA.

Chaebo, G., and J. J. Medeiros. 2017. Conditions for policy implementation via co-production: The control of dengue fever in Brazil. Public Management Review 19 (10): 1381-1398.

Champer, J., J. Liu, S. Y. Oh, R. Reeves, A. Luthra, N. Oakes, A. G. Clark, and P. W. Messer. 2018. Reducing resistance allele formation in CRISPR gene drive. Proceedings of the National Academy of Sciences of the United States of America 115 (21): 5522-5527.

Chandra, G., I. Bhattacharjee, S. N. Chatterjee, and A. Ghosh. 2008. Mosquito control by larvivorous fish. The Indian Journal of Medical Research 127: 13-27.

Chediak, M., F. G. Pimenta, G. E. Coelho, I. A. Braga, J. B. P. Lima, K. R. L. Cavalcante, L. C. de Sousa, M. A. V. de Melo-Santos, M. L. G. Macoris, A. P. de Araújo, C. F. J. Ayres, M. T. M. Andrighetti, R. Gonçalves de Gomes, and R. N. C. Guedes. 2016. Spatial and temporal countrywide survey of temephos resistance in Brazilian populations of Aedes aegypti. Memorias Do Instituto Oswaldo Cruz 111: 311-321.

Chen, S. C., and M. H. Hsieh. 2012. Modeling the transmission dynamics of dengue fever: Implications of temperature effects. Science of the Total Environment 431: 385-391.

Claro, L. B. L., H. Kawa, L. T. Cavallini, and M. L. Garcia Rosa. 2006. Community participation in dengue control in Brazil. WHO Regional Office for South-East Asia. Dengue Bulletin 30: 214-222.

Coelho, G. E. 2012. Challenges in the control of Aedes aegypti. Revista do Instituto de Medicina Tropical de São Paulo 54 (Suppl. 18): S13-14.

De Barro, P. J., B. Murphy, C. C. Jansen, and J. Murray. 2011. The proposed release of the yellow fever mosquito, Aedes aegypti containing a naturally occurring strain of Wolbachia pipientis, a question of regulatory responsibility. Journal of Consumer Protection and Food Safety 6: 33-40.

Degener, C. M., T. M. F. de Ázara, R. A. Roque, C. T. Codeço, A. Araújo Nobre, J. J. Ohly, M. Geier, and Á. E. Eiras. 2014. Temporal abundance of Aedes aegypti in Manaus, Brazil, measured by two trap types for adult mosquitoes. Memórias Do Instituto Oswaldo Cruz 109: 1030-1040.

Degener, C. M., T. M. F. de Ázara, R. A. Roque, S. Rösner, E. S. Oliveira Rocha, E. G. Kroon, C. T. Codeço, A. Araújo Nobre, J. J. Ohly, M. Geier, and A. E. Eiras. 2015. Mass trapping with MosquiTRAPs does not reduce Aedes aegypti abundance. Memórias do Instituto Oswaldo Cruz 110 (4): 517-527.

Díaz, Y., J.-P. Carrera, L. Cerezo, D. Arauz, I. Guerra, J. Cisneros, B. Armién, A. M. Botello, A. B. Araúz, V. Gonzalez, Y. López, L. Moreno, S. López-Vergès, and B. A. Moreno. 2015. Chikungunya virus infection: First detection of imported and autochthonous cases in Panama. The American Journal of Tropical Medicine and Hygiene 92: 482-485.

Dutra, H. L. C., M. N. Rocha, F. B. S. Dias, S. B. Mansur, E. P. Caragata, and L. A. Moreira. 2016. Wolbachia blocks currently circulating Zika virus isolates in Brazilian Aedes aegypti mosquitoes. Cell Host \& Microbe 19: 771-774.

Dyck, V. A., J. Hendrichs, and A. S. Robinson (eds.). 2021. Sterile Insect Technique - Principles and practice in Area-Wide Integrated Pest Management. Second Edition. CRC Press, Boca Raton, Florida, USA. 1200 pp.

El-Sabaawi, R. W., T. C. Frauendorf, P. S. Marques, R. A. Mackenzie, L. R. Manna, R. Mazzoni, D. A. Phillip, M. L. Warbanski, and E. Zandonà. 2016. Biodiversity and ecosystem risks arising from using guppies to control mosquitoes. Biology Letters 12: 20160590.

Evans, B. R., P. Kotsakiozi, A. L. Costa-da-Silva, R. S. Ioshino, L. Garziera, M. C. Pedrosa, A. Malavasi, J. F. Virginio, M. L. Capurro, and J. R. Powell. 2019. Transgenic Aedes aegypti mosquitoes transfer genes into a natural population. Scientific Reports 9: 13047.

Federici, B. A., H.-W. Park, D. K. Bideshi, M. C. Wirth, J. J. Johnson, Y. Sakano, and M. Tang. 2007. Developing recombinant bacteria for control of mosquito larvae. Journal of the American Mosquito Control Association 23 (Suppl. 2): 164-175.

(FIOCRUZ) Oswaldo Cruz Foundation. 2016. Nota Técnica No. 4/2016/IOC-FIOCRUZ/DIRETORIA. Considerações técnicas sobre a aplicação aérea de inseticidas em área urbana.

Flores, H. A., and S. L. O'Neill. 2018. Controlling vector-borne diseases by releasing modified mosquitoes. Nature Reviews Microbiology 16(8): 508-518. 
Franz, A. W. E., I. Sanchez-Vargas, Z. N. Adelman, C. D. Blair, B. J. Beaty, A. A. James, and K. E. Olson. 2006. Engineering RNA interference-based resistance to dengue virus type 2 in genetically modified Aedes aegypti. Proceedings of the National Academy of Sciences of the United States of America 103 (11): 4198-4203.

Franz, A. W. E., I. Sanchez-Vargas, R. R. Raban, W. C. Black IV, A. A. James, and K. E. Olson. 2014. Fitness impact and stability of a transgene conferring resistance to dengue-2 virus following introgression into a genetically diverse Aedes aegypti strain. PLoS Neglected Tropical Diseases 8 (5): e2833.

Frentiu, F. D., T. Zakir, T. Walker, J. Popovici, A. T. Pyke, A. van den Hurk, E. A. McGraw, and S. L. O'Neill. 2014. Limited dengue virus replication in field-collected Aedes aegypti mosquitoes infected with Wolbachia. PLoS Neglected Tropical Diseases 8: e2688.

Furuya-Kanamori, L., S. Liang, G. Milinovich, R. J. S. Magalhaes, A. C. A. Clements, W. Hu, P. Brasil, F. D. Frentiu, R. Dunning, and L. Yakob. 2016. Co-distribution and co-infection of chikungunya and dengue viruses. BMC Infectious Diseases 16: 84.

Garziera, L., M. C. Pedrosa, F. A. Souza, M. Gomez, M. B. Moreira, J. F. Virginio, M. Capurro, and D. O. Carvalho. 2017. Effect of interruption of over-flooding releases of transgenic mosquitoes over wild population of Aedes aegypti: Two case studies in Brazil. Entomologia Experimentalis et Applicata 164: 327-339.

Ghosh, S. K., P. Chakaravarthy, S. R. Panch, P. Krishnappa, S. Tiwari, V. P. Ojha, R. Manjushree, and A. P. Dash. 2011. Comparative efficacy of two poeciliid fish in indoor cement tanks against chikungunya vector Aedes aegypti in villages in Karnataka, India. BMC Public Health 11: 599.

Gubler, D. J., and G. C. Clark. 1996. Community involvement in the control of Aedes aegypti. Acta Tropica 61: 169-179.

Handler, A. M. 2002. Prospects for using genetic transformation for improved SIT and new biocontrol methods. Genetica 116: 137-149.

Harris, A. F., D. Nimmo, A. R. McKemey, N. Kelly, S. Scaife, C. A. Donnelly, C. Beech, W. D. Petrie, and L. Alphey. 2011. Field performance of engineered male mosquitoes. Nature Biotechnology 29: 1034-1037.

Harris, A. F., A. R. McKemey, D. Nimmo, Z. Curtis, I. Black, S. A. Morgan, M. N. Oviedo, R. Lacroix, N. Naish, N. I. Morrison, A. Collado, J. Stevenson, S. Scaife, T. Dafa'alla, G. Fu, C. Phillips, A. Miles, N. Raduan, N. Kelly, C. Beech, C. A. Donnelly, W. D. Petrie, and L. Alphey. 2012. Successful suppression of a field mosquito population by sustained release of engineered male mosquitoes. Nature Biotechnology 30: 828-830.

Healy, K., G. Hamilton, T. Crepeau, S. Healy, I. Unlu, A. Farajollahi, and D. M. Fonseca. 2014. Integrating the public in mosquito management: Active education by community peers can lead to significant reduction in peridomestic container mosquito habitats. PLoS One 9: e108504.

Hendrichs, J., and A. S. Robinson. 2009. Sterile Insect Technique, pp. 953-957. In V. H. Resh, and R. T. Cardé (eds.), Encyclopedia of insects. Second Edition. Academic Press, Burlington, Massachussetts, USA.

Honório, N. A., C. T. Codeço, F. C. Alves, M. A. F. M. Magalhães, and R. Lourenço-De-Oliveira. 2009. Temporal distribution of Aedes aegypti in different districts of Rio de Janeiro, Brazil, measured by two types of traps. Journal of Medical Entomology 46: 1001-1014.

Hood-Nowotny, R., L. Mayr, and B. Knols. 2006. Use of carbon-13 as a population marker for Anopheles arabiensis in a Sterile Insect Technique (SIT) context. Malaria Journal 5(1): 6.

Horstick, O., S. Runge-Ranzinger, M. B. Nathan, and A. Kroeger. 2010. Dengue vector-control services: How do they work? A systematic literature review and country case studies. Transactions of the Royal Society of Tropical Medicine and Hygiene 104(6): 379-386.

Ibrahim, M. A., N. Griko, M. Junker, and L. A. Bulla. 2010. Bacillus thuringiensis. Bioengineered Bugs 1: 31-50.

James, A. A. 2005. Gene drive systems in mosquitoes: Rules of the road. Trends in Parasitology 21 (2): 64-67.

Johnson, B. J., S. A. Ritchie, and D. M. Fonseca. 2017. The state of the art of lethal oviposition trapbased mass interventions for arboviral control. Insects 8(1): 5.

Jupatanakul, N., S. Sim, Y. I. Angleró-Rodríguez, J. Souza-Neto, S. Das, K. E. Poti, S. L. Rossi, N. Bergren, N. Vasilakis, and G. Dimopoulos. 2017. Engineered Aedes aegypti JAK/STAT pathwaymediated immunity to dengue virus. PLoS Neglected Tropical Diseases 11 (1): e0005187.

Kamareddine, L. 2012. The biological control of the malaria vector. Toxins 4(9): 748-767. 
Kant, R., S. Haq, H. C. Srivastava, and V. P. Sharma. 2013. Review of the bioenvironmental methods for malaria control with special reference to the use of larvivorous fishes and composite fish culture in central Gujarat, India. Journal of Vector Borne Diseases 50: 1-12.

Kay, B., and V. S. Nam. 2005. New strategy against Aedes aegypti in Vietnam. The Lancet 365 (9459): 613-617.

Kittayapong, P., S. Yoksan, U. Chansang, C. Chansang, and A. Bhumiratana. 2008. Suppression of dengue transmission by application of integrated vector control strategies at sero-positive GIS-based foci. The American Journal of Tropical Medicine and Hygiene 78: 70-76.

Klassen, W., C. F. Curtis, and J. Hendrichs. 2021. History of the Sterile Insect Technique, pp. 1-44. In V. A. Dyck, J. Hendrichs, and A. S. Robinson (eds.), Sterile Insect Technique - Principles and practice in Area-Wide Integrated Pest Management. Second Edition. CRC Press, Boca Raton, Florida, USA.

Kokoza, V., A. Ahmed, S. Woon Shin, N. Okafor, Z. Zou, and A. S. Raikhel. 2010. Blocking of Plasmodium transmission by cooperative action of Cecropin A and Defensin A in transgenic Aedes aegypti mosquitoes. Proceedings of the National Academy of Sciences of the United States of America 107 (18): 8111-8116.

Lee, H. L., H. Jokob, W. A. Naznia, and S. S. Vasanc. 2009. Comparative life history parameters of transgenic and wild strains of Ae. aegypti in the laboratory. Dengue Bulletin 33: 103-114.

Lees, R. S., B. Knols, R. Bellini, M. Q. Benedict, A. Bheecarry, H. C. Bossin, D. D. Chadee, J. Charlwood, R. K. Dabiré, L. Djogbenou, A. Egyir-Yawson, R. Gato, L. C. Gouagna, M. M. Hassan, S. A. Khan, L. L. Koekemoer, G. Lemperiere, N. C. Manoukis, and J. R. L. Gilles. 2014. Review: Improving our knowledge of male mosquito biology in relation to genetic control programmes. Acta Tropica 132 (Suppl.): S2-S11.

Lees, R. S., D. Carvalho, and J. Bouyer. 2021. Potential impact of the integration of the Sterile Insect Technique in the fight against disease-transmitting mosquitoes, pp. 1081-1118. In V. A. Dyck, J. Hendrichs, and A. S. Robinson (eds.), Sterile Insect Technique - Principles and practice in Area-Wide Integrated Pest Management. Second Edition. CRC Press, Boca Raton, Florida, USA.

Leo, Y. S., A. L. P. Chow, L. K. Tan, D. C. Lye, L. Lin, and L. C. Ng. 2009. Chikungunya outbreak, Singapore, 2008. Emerging Infectious Diseases 15: 836-837.

Lloyd, A. M., M. Farooq, A. S. Estep, R.-D. Xue, and D. L. Kline. 2017. Evaluation of pyriproxyfen dissemination via Aedes albopictus from a point-source larvicide application in northeast Florida. Journal of the American Mosquito Control Association 33 (2): 151-155.

Lorenzi, O. D., C. Major, V. Acevedo, J. Perez-Padilla, A. Rivera, B. J. Biggerstaff, J. MunozJordan, S. Waterman, R. Barrera, and T. M. Sharp. 2016. Reduced incidence of chikungunya virus infection in communities with ongoing Aedes aegypti mosquito trap intervention studies Salinas and Guayama, Puerto Rico, November 2015-February 2016. Morbidity and Mortality Weekly Report 65(18): 479-480.

Luksic, B., N. Pandak, E. Drazic-Maras, S. Karabuva, M. Radic, A. Babic-Erceg, L. Barbic, V. Stevanovic, and T. Vilibic-Cavlek. 2017. First case of imported chikungunya infection in Croatia, 2016. International Medical Case Reports Journal 10: 117-121.

Maciel-de-Freitas, R., R. Aguiar, R. V. Bruno, M. C. Guimarães, R. Lourenço-de-Oliveira, M. H. F. Sorgin, C. J. Struchiner, D. Valle, S. L O'Neill, and L. A. Moreira. 2012. Why do we need alternative tools to control mosquito-borne diseases in Latin America? Memorias Do Instituto Oswaldo Cruz 107: 828-829.

Mackay, A. J., M. Amador, and R. Barrera. 2013. An improved autocidal gravid ovitrap for the control and surveillance of Aedes aegypti. Parasites \& Vectors 6(1): 225.

Mains, J. W., C. L. Brelsfoard, and S. L. Dobson. 2015. Male mosquitoes as vehicles for insecticide. PLoS Neglected Tropical Diseases 9(1): e0003406.

Mains, J. W., C. L. Brelsfoard, R. I. Rose, and S. L. Dobson. 2016. Female adult Aedes albopictus suppression by Wolbachia-infected male mosquitoes. Scientific Reports 6 (September): 33846.

Martelli, C. M. T., J. B. Siqueira, M. P. P. D. Parente, A. L. S. A. Zara, C. S. Oliveira, C. Braga, F. G. Pimenta Junior, F. Cortes, J. G. Lopez, L. R. Bahia, M. C. Ooteman Mendes, M. Q. Machado da Rosa, N. T. Siqueira Filha, D. Constenla, and W. V. Souza. 2015. Economic impact of dengue: Multicenter study across four Brazilian regions. Edited by M. S. Carvalho. PLoS Neglected Tropical Diseases 9 (9): e0004042.

Martins, A. J., J. B. Lima, A. A. Peixoto, and D. Valle. 2009. Frequency of Val1016Ile mutation in the voltage-gated sodium channel gene of Aedes aegypti Brazilian populations. Tropical Medicine \& International Health 14: 1351-1355. 
Maurer-Stroh, S., T.-M. Mak, Y.-K. Ng, S.-P. Phuah, R. G. Huber, J. K. Marzinek, D. A Holdbrook, R. T. C. Lee, L. Cui, and R. T. Lin. 2016. South-east Asian Zika virus strain linked to cluster of cases in Singapore, August 2016. Euro Surveillance 21(38): 30347.

Mendenhall, I. H., M. Manuel, M. Moorthy, T. T. M., Lee, D. H. W. Low, D. Missé, D. J. Gubler, B. R. Ellis, E. E. Ooi, and J. Pompon. 2017. Peridomestic Aedes malayensis and Aedes albopictus are capable vectors of arboviruses in cities. PLoS Neglected Tropical Diseases 11(6): e0005667.

Morales-Pérez, A., E. Nava-Aguilera, J. Legorreta-Soberanis, A. J. Cortés-Guzmán, A. BalanzarMartínez, E. Harris, J. Coloma, V. M. Alvarado-Castro, M. V. Bonilla-Leon, L. Morales-Nava, R. J. Ledogar, A. Cockcroft, and N. Andersson. 2017. Where we put little fish in the water there are no mosquitoes: A cross-sectional study on biological control of the Aedes aegypti vector in 90 coastal-region communities of Guerrero, Mexico. BMC Public Health 17 (Suppl. 1): 433.

(MS) Ministério da Saúde. 2014a. Larvicidas. Brasilia, DF, Brasil.

(MS) Ministério da Saúde. 2014b. Aplicação espacial de inseticidas. Brasilia, DF, Brasil.

(MS) Ministério da Saúde. 2017a. Controle de vetores / Inseticidas e larvicidas. Brasilia, DF, Brasil.

(MS) Ministério da Saúde. 2017b. Zika virus in Brazil: The SUS Response. Brasilia, DF, Brasil.

(MS) Ministério da Saúde. 2017c. Monitoramento dos casos de dengue, febre de chikungunya e febre pelo vírus Zika até a Semana Epidemiológica 4, 2017. Brasilia, DF, Brasil.

(MS/FNS) Ministério da Saúde / Fundação Nacional de Saúde. 2002. Programa Nacional de Controle da Dengue (PNCD). Ministério da Saúde. Fundação Nacional de Saúde Brasilia, DF, Brasil.

(MS/FNS) Ministério da Saúde / Fundação Nacional de Saúde. 2009. Diretrizes nacionais para a prevenção e controle de epidemias de dengue. Secretaria de Vigilancia em Saúde. Brasilia, DF, Brasil.

(NASEM) National Academies of Sciences, Engineering, and Medicine. 2016. Global health impacts of vector-borne diseases: Workshop summary. National Academies Press. Washington DC, USA. 396 pp.

Ndii, M. Z., R. I. Hickson, D. Allingham, and G. N. Mercer. 2015. Modelling the transmission dynamics of dengue in the presence of Wolbachia. Mathematical Biosciences 262: 157-166.

O'Connor, L., C. Plichart, A. C. Sang, C. L. Brelsfoard, H. C. Bossin, and S. L. Dobson. 2012. Open release of male mosquitoes infected with a Wolbachia biopesticide: Field performance and infection containment. Edited by Jason L. Rasgon. PLoS Neglected Tropical Diseases 6 (11): e1797.

Okamoto, K. W., M. A. Robert, A. L. Lloyd, and F. Gould. 2013. A reduce and replace strategy for suppressing vector-borne diseases: Insights from a stochastic, spatial model. PLoS One 8(12): e81860.

Ong, J., X. Liu, J. Rajarethinam, G. Yap, D. Ho, and L. Ching Ng. 2019. A novel entomological index, Aedes aegypti breeding percentage, reveals the geographical spread of the dengue vector in Singapore and serves as a spatial risk indicator for dengue. Parasites \& Vectors 12 (1): 17.

Ooi, E.-E., and D. J. Gubler. 2009. Dengue in Southeast Asia: Epidemiological characteristics and strategic challenges in disease prevention. Cadernos de Saúde Pública 25 (Suppl. 1): S115-S124.

Ooi, E.-E., K.-T. Goh, and D. J. Gubler. 2006. Dengue prevention and 35 years of vector control in Singapore. Emerging Infectious Diseases 12(6): 887-893.

O Silva, M. M., L. B. Tauro, M. Kikuti, R. O. Anjos, V. C. Santos, T. S. F. Gonçalves, I. A. D. Paploski, P. S. S. Moreira, L. C. J. Nascimento, G. S. Campos, A. I. Ko, S. C. Weaver, M. G. Reis, U. Kitron, and G. S. Ribeiro. 2018. Concomitant transmission of dengue, chikungunya and Zika viruses in Brazil: Clinical and epidemiological findings from surveillance for acute febrile illness. Clinical Infectious Diseases 68 (8): 1353-1359.

Paes de Andrade, P., F. J. L. Aragão, W. Colli, O. A. Dellagostin, F. Finardi-Filho, M. H. Hirata, A. de Castro Lira-Neto, M. Almeida de Melo, A. L. Nepomuceno, F. G. da Nóbrega, G. D. de Sousa, F. H. Valicente, and M. H. B. Zanettini. 2016. Use of transgenic Aedes aegypti in Brazil: Risk perception and assessment. Bulletin of the World Health Organization 94(10): 766-771.

(PAHO) Pan American Health Organization. 2016. Vector borne diseases in the region of the Americas (2013-2016). Washington, DC, USA.

(PAHO) Pan American Health Organization. 2018. Integrated management strategy for dengue prevention and control in the region of the Americas. Washington, DC, USA.

(PAHO/WHO) Pan American Health Organization / World Health Organization. 2003. 44th Directing Council. 22-26 September 2003. Washington, DC, USA.

(PAHO/WHO) Pan American Health Organization / World Health Organization. 2014. Number of reported cases of chikungunya fever in the Americas by country or territory 2013-2014. Washington, DC, USA. 
(PAHO/WHO) Pan American Health Organization / World Health Organization. 2016. Zika suspected and confirmed cases reported by countries and territories in the Americas, 2015-2017, cumulative cases. Washington, DC, USA.

Parks, W., and L. Lloyd. 2004. Planning social mobilization and communication for dengue fever prevention and control: A step-by-step guide. UNDP/World Bank/WHO Special Programme for Research and Training in Tropical Diseases. World Health Organization. Geneva, Switzerland. 138 pp.

Paz-Soldan, V. A., J. Yukich, A. Soonthorndhada, M. Giron, C. S. Apperson, L. Ponnusamy, C. Schal, A. C. Morrison, J. Keating, and D. M. Wesson. 2016. Design and testing of novel lethal ovitrap to reduce populations of Aedes mosquitoes: Community-Based Participatory Research between Industry, Academia and Communities in Peru and Thailand PLoS One 11 (8): e0160386

Perich, M. J., A. Kardec, I. A. Braga, I. F. Portal, R. Burge, B. C. Zeichner, W. A. Brogdon, and R. A. Wirtz. 2003. Field evaluation of a lethal ovitrap against dengue vectors in Brazil. Medical and Veterinary Entomology 17: 205-210.

Pessanha, J. E. M., W. T. Caiaffa, C. C. César, and F. A. Proietti. 2009. Avaliação do plano nacional de controle da dengue. Cadernos de Saúde Pública 25(7): 1637-1641.

Pruszynski, C. A., L. J. Hribar, R. Mickle, and A. L. Leal. 2017. A large scale biorational approach using Bacillus thuringiensis israelensis (strain AM65-52) for managing Aedes aegypti populations to prevent dengue, chikungunya and Zika transmission. PLoS One 12(2): e0170079.

Regis, L., A. M. Monteiro, M. A. V. de Melo-Santos, J. C. Silveira Jr, A. F. Furtado, R. V. Acioli, G. M. Santos, M. Nakazawa, M. S. Carvalho, P. J. Ribeiro Jr, and W. V. de Souza. 2008. Developing new approaches for detecting and preventing Aedes aegypti population outbreaks: Basis for surveillance, alert and control system. Memorias Do Instituto Oswaldo Cruz 103: 50-59.

Regis, L. N., R. V. Acioli, J. C. Silveira Jr, M. A. V. Melo-Santos, W. V. Souza, C. M. N. Ribeiro, J. C. S. da Silva, A. M. Vieira Monteiro, C. M. F. Oliveira, R. M. R. Barbosa, C. Braga, M. A. Benedetti Rodrigues, M. Gomes N. M. Silva, P. J. Ribeiro Jr., W. H. Bonat, L. C. de Castro Medeiros, M. Sa Carvalho, and A. F. Furtado. 2013. Sustained reduction of the dengue vector population resulting from an integrated control strategy applied in two Brazilian cities. PLoS One 8(7): e67682.

Ritchie, S. A., L. P. Rapley, C. Williams, P. H. Johnson, M. Larkman, R. M. Silcock, S. A. Long, and R. C. Russell. 2009. A lethal ovitrap-based mass trapping scheme for dengue control in Australia: I. Public acceptability and performance of lethal ovitraps. Medical and Veterinary Entomology 23 (4): 295-302.

Rodriguez-Morales, A. J., W. E. Villamil-Gómez, and C. Franco-Paredes. 2016. The arboviral burden of disease caused by co-circulation and co-infection of dengue, chikungunya and Zika in the Americas. Travel Medicine and Infectious Disease 14 (3): 177-179.

Rosenbaum, J., M. B. Nathan, R. Ragoonanansingh, S. Rawlins, C. Gayle, D. D. Chadee, and L. S. Lloyd. 1995. Community participation in dengue prevention and control: A survey of knowledge, attitudes, and practice in Trinidad and Tobago. The American Journal of Tropical Medicine and Hygiene 53(2): 111-117.

Rückert, C., J. Weger-Lucarelli, S. M. Garcia-Luna, M. C. Young, A. D. Byas, R. A. Murrieta, J. R. Fauver, and G. D. Ebel. 2017. Impact of simultaneous exposure to arboviruses on infection and transmission by Aedes aegypti mosquitoes. Nature Communications 8: 15412.

Samuel, M., D. Maoz, P. Manrique, T. Ward, S. Runge-Ranzinger, J. Toledo, R. Boyce, and $\mathbf{O}$. Horstick. 2017. Community effectiveness of indoor spraying as a dengue vector control method: A systematic review. PLoS Neglected Tropical Diseases 11(8): e0005837.

San Martín, J. L., and O. Brathwaite-Dick. 2007. La estrategia de gestión integrada para la prevención y el control del dengue en la región de las Américas. Revista Panamericana de Salud Pública 21: 5563.

Sanchez, L., J. Maringwa, Z. Shkedy, M. Castro, N. Carbonell, and P. Van der Stuyft. 2012. Testing the effectiveness of community-based dengue vector control interventions using semiparametric mixed models. Vector-Borne and Zoonotic Diseases 12(7): 609-615.

(SHS) Secretariat of Health Surveillance. 2017. Health Brazil 2015/2016. An analysis of health situation and the epidemic caused by Zika virus and other diseases transmitted by Aedes aegypti. Ministry of Health of Brazil. Braslia, DF, Brazil. 132 pp.

Sinkins, S. P. 2004. Wolbachia and cytoplasmic incompatibility in mosquitoes. Insect Biochemistry and Molecular Biology 34(3): 723-729. 
Sithiprasasna, R., P. Mahapibul, C. Noigamol, M. J. Perich, B. C. Zeichner, B. Burge, S. L. Norris, J. W. Jones, S. S. Schleich, and R. E. Coleman. 2003. Field evaluation of a lethal ovitrap for the control of Aedes aegypti (Diptera: Culicidae) in Thailand. Journal of Medical Entomology 40(4): 455462.

Sommerfeld, J., and A. Kroeger. 2015. Innovative community-based vector control interventions for improved dengue and chagas disease prevention in Latin America: Introduction to the Special Issue. Transactions of the Royal Society of Tropical Medicine and Hygiene 109 (2): 85-88.

Spiegel, J., A. Yassi, and R. Tate. 2002. Dengue in Cuba: Mobilisation against Aedes aegypti. The Lancet Infectious Diseases 2(4): 207-208.

(SS-PE) Secretaria de Saúde de Pernambuco (2015). Boletim epidemiológico arboviroses transmitidas pelo Aedes aegypti. Pernambuco, Brasil.

Suter, T., M. M. Crespo, M. F. de Oliveira, T. S. A. de Oliveira, M. A. V. de Melo-Santos, C. M. F. de Oliveira, C. F. J. Ayres, R. M. Rodrigues Barbosa, A. P. Araújo, L. N. Regis, E. Flacio, L. Engeler, P. Müller, and M. H. N. L. Silva-Filha. 2017. Insecticide susceptibility of Aedes albopictus and Ae. aegypti from Brazil and the Swiss-Italian border region. Parasites \& Vectors 10(1): 431.

Suwannapong, N., M. Tipayamongkholgul, A. Bhumiratana, C. Boonshuyar, N. Howteerakul, and S. Poolthin. 2014. Effect of community participation on household environment to mitigate dengue transmission in Thailand. Tropical Biomedicine 31: 149-158.

Suwanmanee, S., P. Surasombatpattana, N. Soonthornworasiri, R. Hamel, P. Maneekan, D. Missé, and N. Luplertlop. 2018. Monitoring arbovirus in Thailand: Surveillance of dengue, chikungunya and Zika virus, with a focus on coinfections. Acta Tropica 188: 244-250.

Tapia-Conyer, R., J. Méndez-Galván, and P. Burciaga-Zúñiga. 2012. Community participation in the prevention and control of dengue: The patio limpio strategy in Mexico. Pediatrics and International Child Health 32 (Suppl. 1): 10-14.

Tauil, P. L. 2002. Aspectos críticos do controle do dengue no Brasil. Cadernos de Saúde Pública 18 (June): 867-871.

Townson, H., M. B. M. Nathan, M. Zaim, P. Guillet, L. Manga, R. Bos, and M. Kindhauser. 2005. Exploiting the potential of vector control for disease prevention. Bulletin of the World Health Organization 83(12): 942-947.

Travanty, E. A., Z. N. Adelman, A. W. Franz, K. M. Keene, B. J. Beaty, C. D. Blair, A. A. James, and K. E. Olson. 2004. Using RNA interference to develop dengue virus resistance in genetically modified Aedes aegypti. Insect Biochemistry and Molecular Biology 34(7): 607-613.

Ulibarri, G., B. Betanzos, M. Betanzos, and J. J. Rojas. 2016. Control of Aedes aegypti in a remote Guatemalan community vulnerable to dengue, chikungunya and Zika virus: Prospective evaluation of an integrated intervention of web-based health worker training in vector control, low-cost ecological ovillantas, and community engagement. F1000Research 5: 598.

Unckless, R. L., A. G. Clark, and P. W. Messer. 2017. Evolution of resistance against CRISPR/Cas9 gene drive. Genetics 205(2): 827-841.

Unlu, I., D. S. Suman, Y. Wang, K. Klingler, A. Faraji, and R. Gaugler. 2017. Effectiveness of autodissemination stations containing pyriproxyfen in reducing immature Aedes albopictus populations. Parasites \& Vectors 10(1): 139.

Unlu, I., G. M. Williams, I. Rochlin, D. Suman, Y. Wang, K. Chandel, and R. Gaugler. 2018. Evaluation of lambda-cyhalothrin and pyriproxyfen barrier treatments for Aedes albopictus (Diptera: Culicidae) management in urbanized areas of New Jersey. Journal of Medical Entomology 55 (2): 472-76.

(US-EPA) United States Environmental Protection Agency. 2017. Success in mosquito control: An integrated approach. Washington, DC, USA.

Van den Berg, H., C. M. Mutero, and K. Ichimori. 2012. Guidance on policy-making for Integrated Vector Management. Department of Control of Neglected Tropical Diseases, World Health Organization, Geneva, Switzerland. 11 pp.

Van den Hurk, A. F., S. Hall-Mendelin, A. T. Pyke, F. D. Frentiu, K. McElroy, A. Day, S. Higgs, and S. L. O'Neill. 2012. Impact of Wolbachia on infection with chikungunya and yellow fever viruses in the mosquito vector Aedes aegypti. PLoS Neglected Tropical Diseases 6(11): e1892.

Vanlerberghe, V., M. E. Toledo, M. Rodríguez, D. Gomez, A. Baly, J. R. Benitez, and P. Van der Stuyft. 2009. Community involvement in dengue vector control: Cluster randomised trial. BMJ 338: b1959. 
Vreysen, M. J. B., K. Saleh, F. Mramba, A. Parker, U. Feldmann, V. A. Dyck, A. Msangi, and J. Bouyer. 2014. Sterile insects to enhance agricultural development: The case of sustainable tsetse eradication on Unguja Island, Zanzibar, using an Area-Wide Integrated Pest Management approach. PLoS Neglected Tropical Diseases 8(5): e2857.

Vreysen, M. J. B. 2021. Monitoring sterile and wild insects in Area-Wide Integrated Pest Management programmes, pp. 485-528. In V. A. Dyck, J. Hendrichs, and A. S. Robinson (eds.), Sterile Insect Technique - Principles and practice in Area-wide Integrated Pest Management. Second Edition. CRC Press, Boca Raton, Florida, USA.

Walshe, D. P., P. Garner, A. A. Abdel-Hameed Adeel, G. H. Pyke, and T. Burkot. 2013. Larvivorous fish for preventing malaria transmission. Cochrane Database of Systematic Reviews 10 (12): CD008090.

(WHO) World Health Organization. 2004. Global strategic framework for Integrated Vector Management. Geneva, Switzerland.

(WHO) World Health Organization. 2008. Position statement on Integrated Vector Management. Geneva, Switzerland.

(WHO) World Health Organization. 2009. Dengue guidelines for diagnostics, treatment, prevention and control. Geneva, Switzerland.

(WHO) World Health Organization. 2013. WHO recommended insecticides for indoor residual spraying against malaria vectors. Geneva, Switzerland.

(WHO) World Health Organization. 2016a. Dengue and severe dengue. Geneva, Switzerland.

(WHO) World Health Organization. 2016b. Zika Strategic Response Plan Quarterly. Geneva, Switzerland.

(WHO) World Health Organization. 2016c. Number of reported cases of Chikungunya fever in the Americas in 2016. Geneva, Switzerland.

(WHO) World Health Organization. 2017a. Situation report: Zika virus, microcephaly, Guillain-Barré Syndrome, 10 March 2017. Situation Report. Geneva, Switzerland.

(WHO) World Health Organization. 2017b. Chikungunya. Geneva, Switzerland.

(WHO) World Health Organization. 2017c. Global vector control response 2017-2030. Geneva, Switzerland.

(WHO) World Health Organization. 2017d. Dengue control strategies. Geneva, Switzerland.

(WHO) World Health Organization. 2017e. Environmental management. Geneva, Switzerland.

(WHO) World Health Organization. 2017f. Chemical control. Geneva, Switzerland.

(WHO) World Health Organization. 2018. Yellow fever.

Zabalou, S., A. Apostolaki, I. Livadaras, G. Franz, A. S. Robinson, C. Savakis, and K. Bourtzis. 2009. Incompatible Insect Technique: Incompatible males from a Ceratitis capitata genetic sexing strain. Entomologia Experimentalis et Applicata 132: 232-240.

Zahir, A. 2016. Community participation, dengue fever prevention and practices for control in Swat, Pakistan. International Journal of Maternal and Child Health and AIDS 5: 39-45.

Zanluca, C., V. C. A. de Melo, A. L. P. Mosimann, G. I. V. dos Santos, C. N. D. dos Santos, and K. Luz. 2015. First report of autochthonous transmission of Zika virus in Brazil. Memórias Do Instituto Oswaldo Cruz 110: 569-572.

Zara, A. L. S. A., S. M. Santos, E. S. Fernandes-Oliveira, R. G. Carvalho, and G. E. Coelho, 2016. Aedes aegypti control strategies: A review. Epidemiologia e Serviços de Saúde 25(2): 391-404. 